\title{
ABC of Brain Stem Death
}

\section{FROM BRAIN DEATH TO BRAIN STEM DEATH}

\section{Historical background}

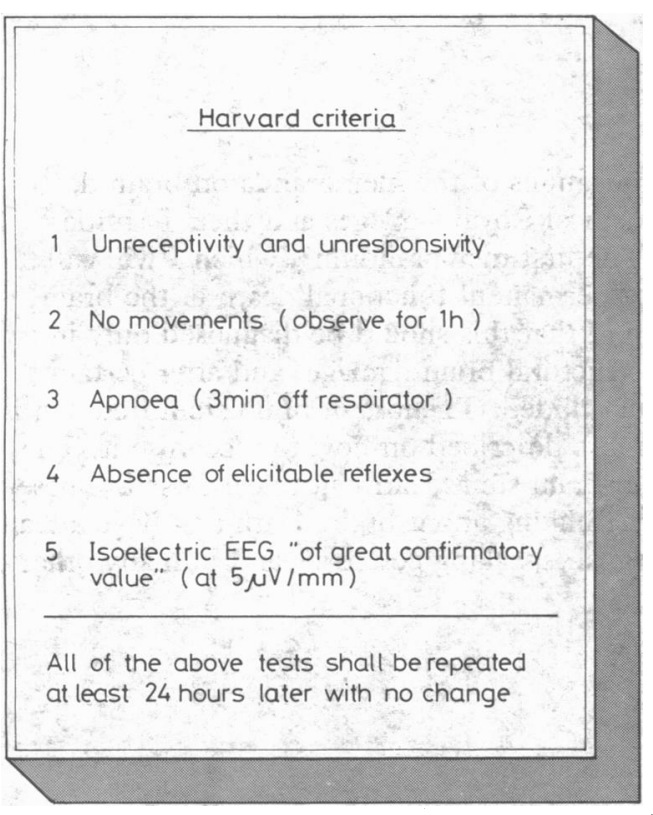

\section{The first insight}

"What we are attempting to define and establish beyond reasonable doubt is the state of irreversible damage to the brain stem. It is the point of no return.

Mohandas and $\mathrm{Chou}^{4}$
Brain death was first described clinically in 1959 when two French physicians ${ }^{1}$ identified a condition they called "coma dépassé"-literally, a state beyond coma. Twenty of their 23 patients were suffering from primary intracranial disorders and the other three from the cerebral sequelae of cardiorespiratory arrest. All the classic features of brain death are found in this early report. Articles published in the early 1960s already suggested that the cerebral circulation was "blocked" by raised intracranial pressure in most of these cases.

The report of the Ad Hoc Committee of the Harvard Medical School in $1968^{2}$ brought awareness of brain death to a much wider audience. The Harvard criteria demanded that the patient should be unreceptive and unresponsive, the most intensely painful stimuli evoking "no vocal or other response, not even a groan, withdrawal of a limb or quickening of respiration." There had to be no movements during observation for one hour. Apnoea was to be confirmed by three minutes off the respirator (the centrality of apnoea, properly defined and tested for, had already been appreciated). The Harvard criteria also required that there should be "no reflexes," the emphasis being on brain stem reflexes. A flat or isoelectric electroencephalogram at high gain was of "great confirmatory value." All the tests were to be repeated at least 24 hours later, with no change in the findings.

The report unambiguously proposed that this clinical state should be accepted as death; recognised the moral, ethical, religious, and legal implications; and boldly saw itself as preparing the way "for better insight into all these matters as well as for better law than is currently applicable." A year later Beecher, the chairman of the Harvard committee, stated that this body was "unanimous in its belief that an electroencephalogram was not essential to a diagnosis of irreversible coma," although it could provide "valuable supporting data."3

Within three years of this radical yet humane proposal two neurosurgeons from Minneapolis made the challenging suggestion that "in patients with known but irreparable intracranial lesions" irreversible damage to the brain stem was the "point of no return." The diagnosis "could be based on clinical judgment." 4

The Minnesota workers introduced the notion of aetiological preconditions. (Twenty of their 25 patients had sustained massive craniocerebral trauma and the others were suffering from other primary intracranial disorders.) They emphasised the importance of apnoea to the determination of brain death; in fact, they insisted on four minutes of disconnection from the respirator. They demanded absent brain stem reflexes, stated that the findings should not change for at least 12 hours, and emphasised that the electroencephalogram was not mandatory for the diagnosis. Their recommendations later became known as the Minnesota criteria and were to influence thinking and practice in the UK considerably. I am emphasising this because it has been suggested that physicians in the UK have been overcritical of much American work on this subject. 


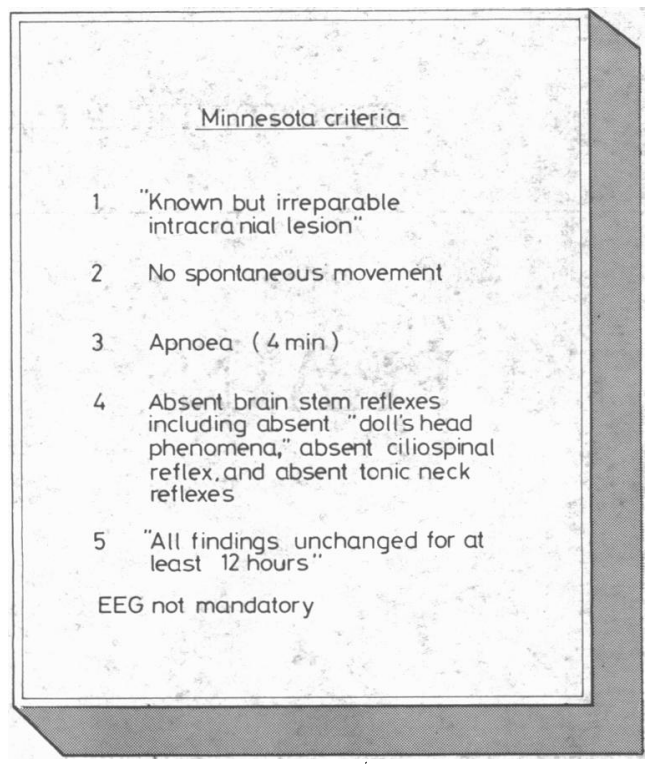

Since 1971 doctors have sought to identify the sufficient component (or physiological kernel) of brain death. It was soon realised that absent tendon reflexes (demanded in both the French and Harvard criteria) really implied loss of function of the spinal cord and that this was irrelevant to a diagnosis of brain death. Death of the brain and death of the whole nervous system are not the same thing. If the heart beat continues for long enough many patients with dead brains will recover their tendon reflexes or show pathological limb reflexes. ${ }^{5}$ The presence or absence of such reflexes, while providing useful clues whether the spinal cord is alive or dead, tell us nothing about whether the brain stem is functioning or not. Spinal areflexia is in fact the exception in brain death (established by the angiographic demonstration of a non-perfused brain). ${ }^{6}$

There has also been a systematic attempt to look critically at the meaning of minimal cellular activity - above the level of a dead brain stem. It was gradually realised that the cardiac prognosis depended critically on whether the brain stem was functioning or not. If the brain stem was dead the heart would stop quite soon. The presence of very low voltage residual electroencephalographic activity-seen in a few cases-did not influence the outcome. Such activity usually subsided anyway before asystole supervened.

\section{Irreversible loss of brain stem function}

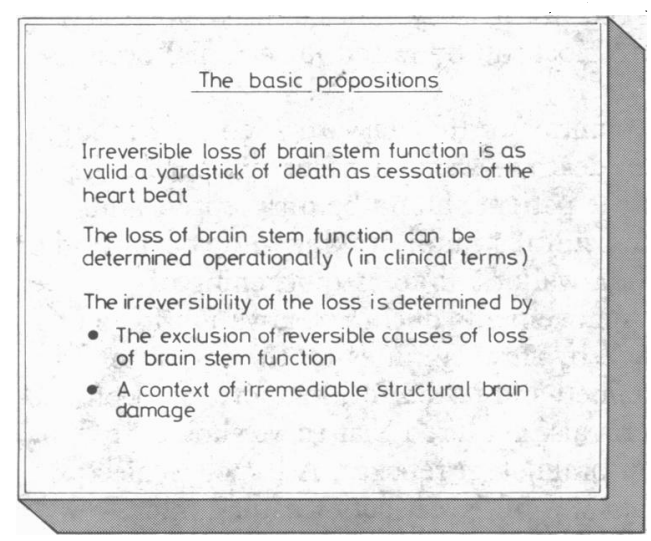

\section{What the proposals imply}

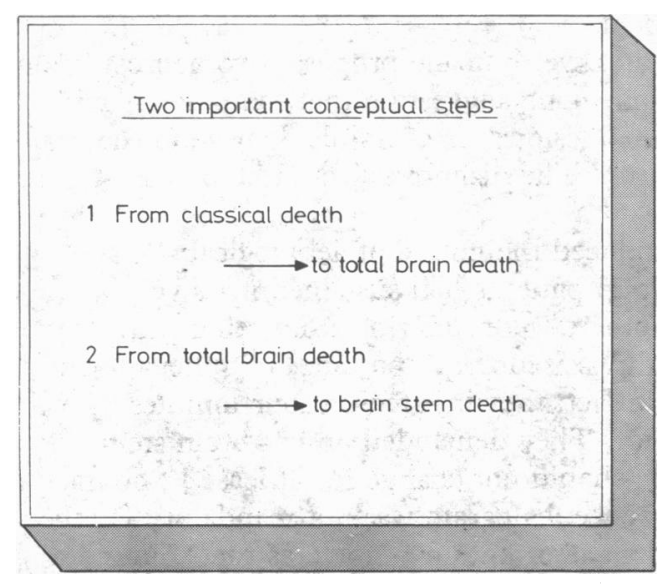

The table highlights the implications of the memoranda on brain death issued by the Conference of Medical Royal Colleges and their Faculties in the UK in 1976 and 1979. The first memorandum ${ }^{7}$ (which I will call the UK code) emphasises that "permanent functional death of the brain stem constitutes brain death" and that this should be diagnosed only in a defined context (irremediable structural brain damage) and after certain specified conditions have been excluded. The loss of brain stem function is assessed clinically. Simple tests are described on how to recognise it. The second memorandum ${ }^{8}$ identifies brain stem death with death itself. These documents mark a milestone in thinking about brain death and have already influenced practice in most English-speaking countries and in many others.

Two major strides are necessary before one can accept the propositions implicit in the UK code. ${ }^{7}$ The first is the step from "classical" death to whole brain death. In most countries medical opinion has accepted the basic concept of brain death, although there are still a few influenced by religious or other considerations who oppose it. ${ }^{910}$ Leading spokesmen of all the main Western religions have endorsed it, ${ }^{11}$ and publications on the subject are numerous. ${ }^{12-14}$

Doctors were still taking this first step when they were faced with another challenge: that death of the brain stem was the necessary and sufficient component of whole brain death. I have already explained (see first article) how death of the brain stem relates to a philosophical concept of death (the irreversible loss of the capacity for consciousness and the capacity to breathe). The task is now to convince people that this condition can be identified clinically - and that it is not in conflict with more traditional notions of brain death or of death itself. If we accept the concept of brain stem death it might be wise to change the words we use and no longer speak of "brain death" when we mean "brain stem death."

Some neurologists - and many experts in electroencephalography-have been caught off balance by these essentially conceptual, rather than technological, developments. Some of the main proponents of the idea of whole brain death (their first battle won, the role of their electroencephalographs well defined, their areas of skill widely accepted) have proved reluctant to move a little further. 


\section{Functions of the brain stem}

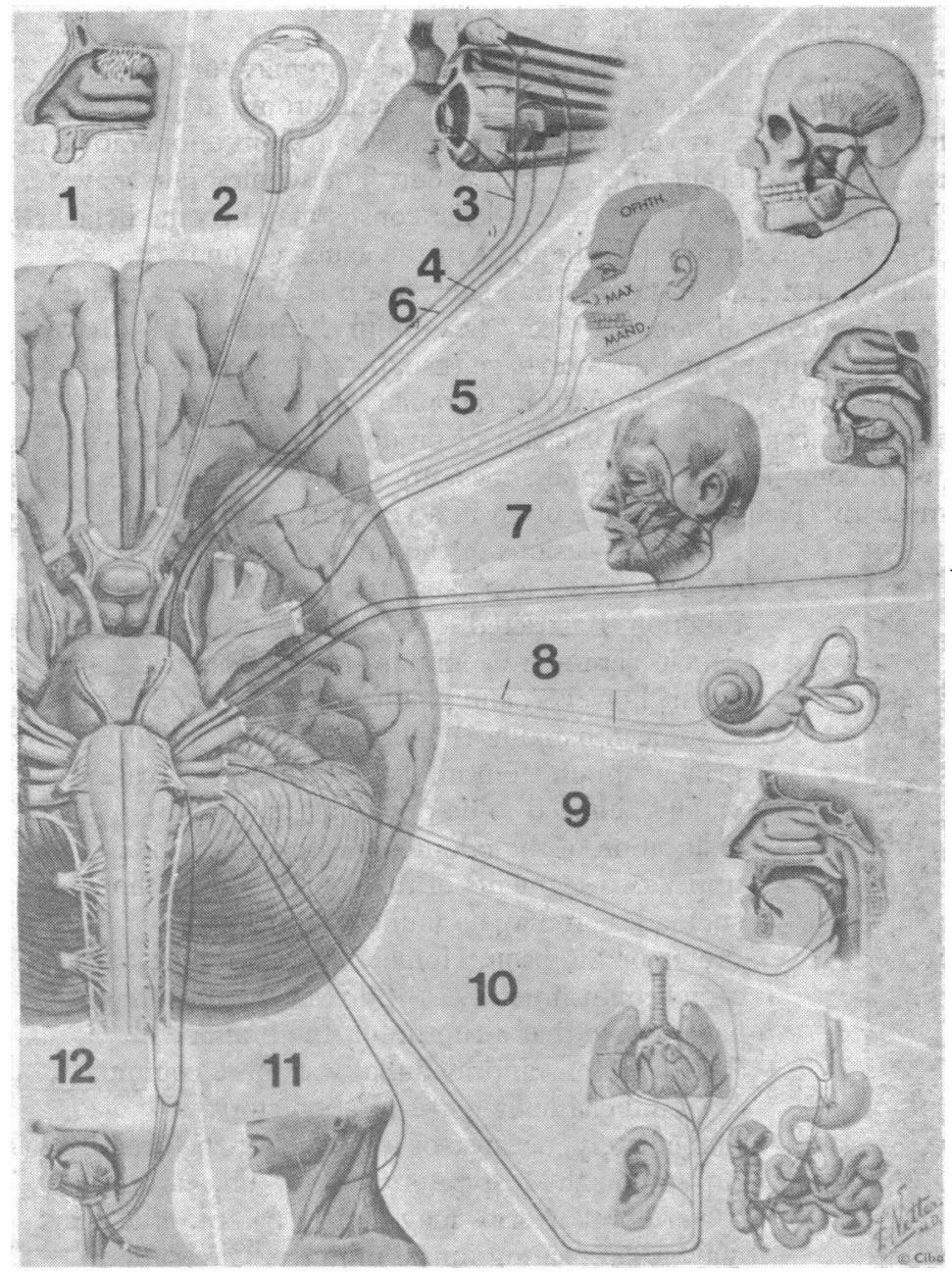

As well as being essential for maintaining breathing, the brain stem is necessary for the proper functioning of the cortex. It has long been known that small, strategically situated lesions of the brain stem, of acute onset and affecting the paramedian tegmental area bilaterally, might cause prolonged coma ${ }^{15} 16$ because they damage critical parts of the "ascending reticular activating system."

The reticular formation constitutes the central core of the brain stem and projects to wide areas of the limbic system and neocortex. Projections from the upper part of the brain stem are responsible for alerting mechanisms. These can be thought of as generating the capacity for consciousness. The content of consciousness (what a person knows, thinks, or feels) is a function of activated cerebral hemispheres. But, unless there is a functioning brain stem, "switching on" the hemispheres, one cannot speak of such a content. There is evidence that brain stem injury in man may massively reduce cerebral oxidative metabolism, ${ }^{17}$ cerebral blood flow, ${ }^{18}$ or both. ${ }^{19}$ Apart from mechanisms essential for respiration, the brain stem contains others which contribute to maintaining blood pressure. All the motor outputs from the hemispheres have to travel through the brain stem, as do all the sensory inputs to the brain (other than sight and smell).

Because the brain stem nuclei are so near one another brain stem function can be clinically evaluated in a unique way. Testing the various cranial nerve reflexes probes the brain stem slice by slice, as if it were salami. Respiratory function can also be assessed very accurately. An acute, massive, and irreversible brain stem lesion (primary or secondary) prevents meaningful functioning of the "brain as a whole," even if isolated parts of the brain may, for a short while, still emit signals of biological activity.

The difference between functional death (death of the organism as a whole) and total cellular death (death of the whole organism) has already been emphasised. The table summarises the parallel argument in relation to the brain as a whole and the whole brain.

\section{Mechanisms of brain stem death}
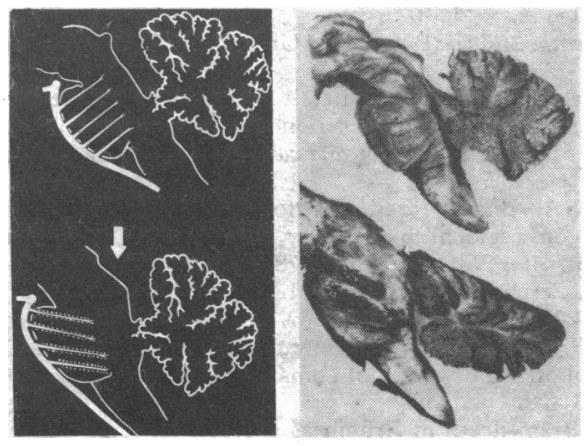

The brain stem may be damaged by a primary lesion or because raised pressure in the supratentorial or infratentorial compartments of the skull has had catastrophic effects on its blood supply and structural integrity. Direct hypoxic damage affects the cortex more than the brain stem. Brain stem damage in hypoxic encephalopathy is often the result of coning due to cerebral oedema. Several factors may operate in any given case.

A severe head injury may be associated with a pronounced rise of intracranial pressure, even in the absence of a subdural or extradural haemorrhage. Similar rises may be seen after subarachnoid haemorrhage. Intracranial hypertension is also a feature of the cerebral oedema that almost invariably complicates acute anoxic insults to the brain. The initial effects, in such cases, are often complicated by the development of various intracranial "shifts." There may be downward-spreading oedema and caudal displacement of the diencephalon and brain stem with stretching 


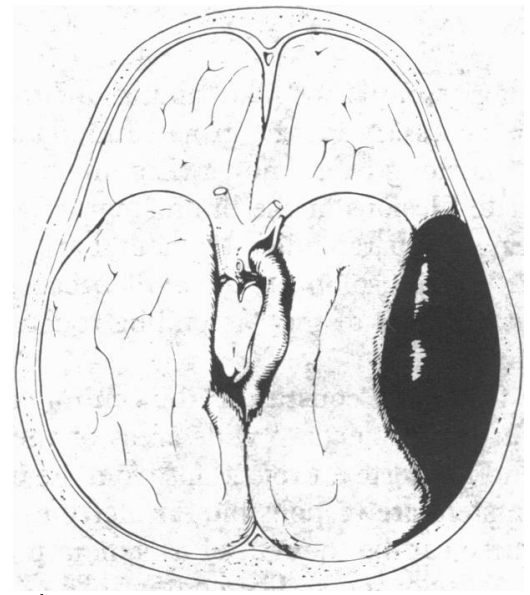

of the perforating pontine branches of the basilar artery and secondary haemorrhages in their territory. Or the brain stem may be compressed from uncal herniation into the tentorial opening.

A pressure cone at the level of the foramen magnum may further damage the brain stem. Venous drainage may be compromised. Ischaemic changes may be striking. If ventilation is continued at room temperature in the presence of a dead brain autolysis will occur. The whole brain may liquefy. Fragments of the destroyed cerebellar tonsils may become detached and be found even as far away as the roots of the cauda equina.

About half the patients in whom brain stem death is diagnosed in the United Kingdom have sustained a recent head injury. Another 30\% have had a very recent intracranial haemorrhage (usually subarachnoid, from a ruptured aneurysm).${ }^{20}$ Other primary intracranial conditions are abscess, meningitis, and encephalitis. Cardiac and respiratory arrest, and cerebral hypoperfusion complicating profound shock, are relatively rare, causes of brain stem death. They result more often in a vegetative state.

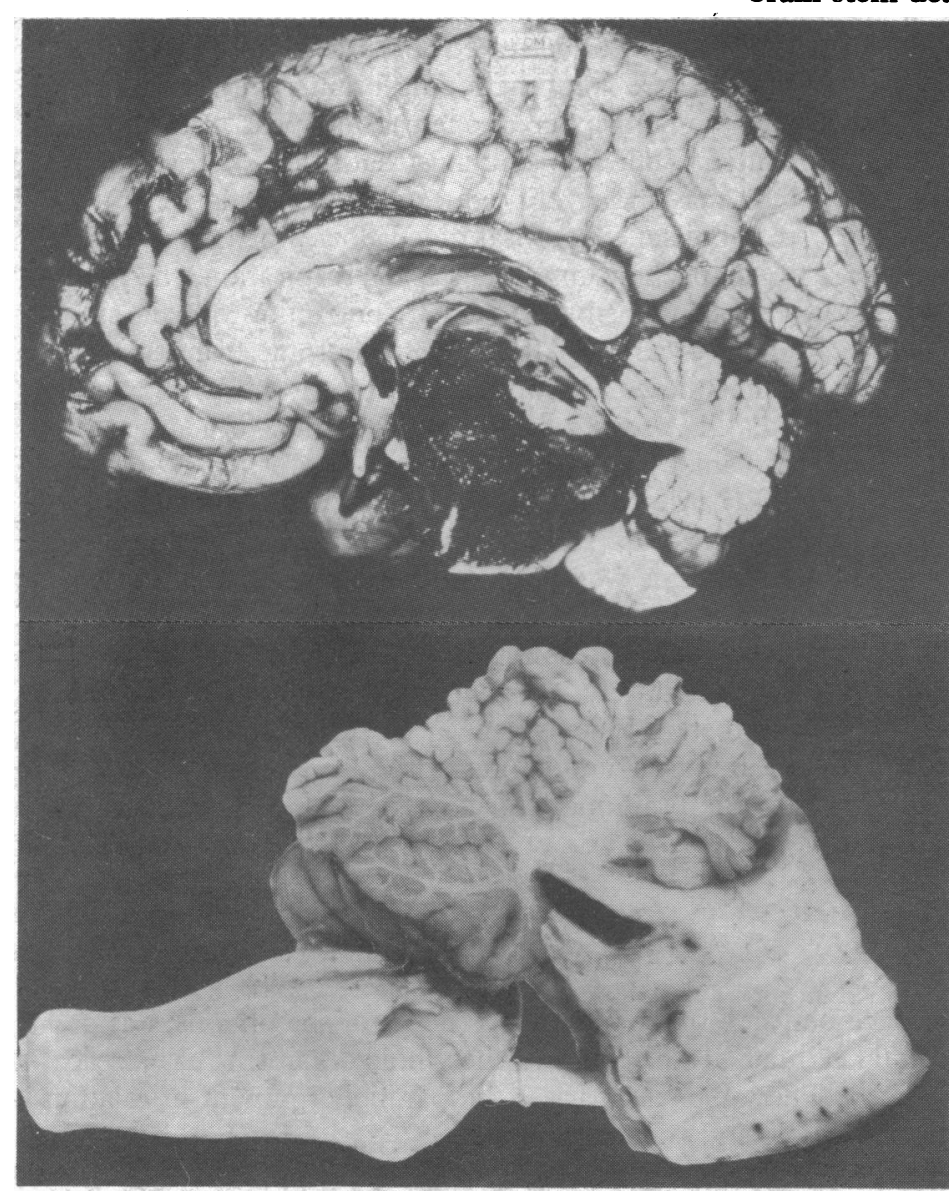

The illustration of cranial nerves is reproduced from the Ciba Collection of Medical Illustrations by courtesy of CIBA-GEIGY Ltd, Basle; that of downward displacement of the dorsal part of the brain stem from Johnson RT, Acta Radiologica 1956;46:250-6; and that of a brain stem after judicial hanging by permission of Professor Keith Simpson.

Dr Christopher Pallis, DM, FRCP, is reader emeritus in neurology, Royal Postgraduate Medical School, London.

${ }^{1}$ Mollaret P, Goulon M. Le coma dépassé (mémoire préliminaire). Rev Neurol 1959;101:3-15.

${ }^{2}$ Ad Hoc Committee of the Harvard Medical School. A definition of irreversible coma. $\mathcal{F} A M A$ 1968;205:85-8.

3 Beecher HK. After the "definition of irreversible coma." $N$ Engl f Med $1969 ; 281: 1070-1$.

4 Mohandas A, Chou SN. Brain death-a clinical and pathological study. f Neurosurg $1971 ; 35: 211-8$.

5 Ivan LP. Spinal reflexes in cerebral death. Neurology 1973;23:650-2.

6 Jørgensen EO. Spinal man after brain death. Acta Neurochir 1973;28: 259-73.

7 Conference of Medical Royal Colleges and their Faculties in the UK. Diagnosis of death. Br Med $\mathcal{F} 1976$;ii:1187-8.

${ }^{8}$ Conference of Medical Royal Colleges and their Faculties in the UK. Diagnosis of death. Br Med f 1979;i :3320.
Primary lesions of the brain stem (haemorrhages or infarcts) seldom cause total loss of brain stem function. Restricted lesions (causing restricted deficits) are more common. Massive lesions may occur, however, and result in brain stem death.

Judicial hanging is another cause of lethal, primary brain stem injury. Death in such cases is widely believed to be due to a fracturedislocation of the odontoid, with compression of the upper two segments of the spinal cord. Although such a lesion may be found in some cases, Professor Simpson, Home Office Pathologist when capital punishment was still resorted to in the UK, has told me that a rupture of the brain stem (between pons and medulla) was more common.

In judicial hanging respiration stops immediately, because of the effect of the brain stem rupture on the respiratory centre. The carotid or vertebral arteries may remain patent. The heart may go on beating for 20 minutes. Circulation continues, and parts of the brain are probably irrigated with blood (od diminishing oxygen saturation) for several minutes. I would guess that an electroencephalogram might for a short while continue to show some activity, despite the mortal injury to the brain stem. Is such an individual alive or dead? The very posing of such a question forces one to focus attention on the reversibility or irreversibility of the brain stem lesion and away from extraneous considerations.

9 Byrne PA, O'Reilly S, Quay PM. Brain death-an opposing viewpoint. FAMA 1979;242:1985-90.

${ }^{10}$ Evans DW, Lum LC. Cardiac transplantation. Lancet 1980;i :933-4.

11 Veith FJ, Fein JM, Tendler MD, et al. Brain death. A status report of medical and ethical considerations. FAMA 1977;238:1651-5.

12 Smith AJK, Penry JK, eds. Brain death: a bibliography with key-word and author indexes. Bethesda: NINDS, 1972. (Bibliography Series No 1.)

${ }^{13}$ Korein J, ed. Brain death: interrelated medical and social issues. Ann NY Acad Sci 1978;315:1-442.

14 Walker AE. Cerebral death. 2nd ed. Baltimore: Urban and Schwarzenberg, 1981.

${ }^{15}$ Plum F. Organic disturbances of consciousnesss. In: Critchley M, Jennett B, eds. Scientific foundations of neurology. London: Heinemann, 1972.

${ }^{16}$ Plum F, Posner JB. The diagnosis of stupor and coma. 3rd ed. Philadelphia: Davis, 1980.

${ }^{17}$ Hass WK, Hawkins RA. Bilateral reticular formation lesions causing coma: their effects on regional blood flow, glucose utilisation and oxidative metabolism. Ann NY Acad Sci 1978;315:105-9.

${ }^{18}$ Heiss WD, Jellinger K. Cerebral blood flow and brainstem lesion. Zeitschrift für Neurologie 1972 ;203:197-209.

19 Ingvar DH, Sorander P. Destruction of the reticular core of the brainstem: a pathoanatomical follow-up of a case of coma of three years' duration. Arch Neurol 1970;23:1-8.

${ }^{20}$ Jennett B, Hessett C. Brain death in Britain as reflected in renal donors. Br Med F $1981 ; 283: 359-62$. 